\title{
Estetik dalam Puisi Dunya al-Imam al-Shafi'i
}

\author{
The Aesthetics in the Poetry of Dunya by al-Imam al-Shafi'i \\ MOKTAR HUSSAIN* \& KHAZRI OSMAN ${ }^{1}$
}

\begin{abstract}
Every element in a piece of work, which creates either explicit or implicit, is mutually related to each other. Among the aspects that can be examined to elevate the status of a particular work is the aesthetic value of its language. The early scholars have expertise in all branches of knowledge, however, they still highlight the elements of language in their works. Among the earliest known scholars is alImam al-Shafi'i. His authority in the field of fiqh and principals of fiqh is undeniable. However, people did not recognize him as a figure for Arabic literature. Therefore, the current study has to be done to highlight his abilities in terms of Arabic language because of the recognition of many scholars. The study used a qualitative method by making content analysis as a research design. Data collection was done on works that were related to Dunia, then they were analyzed from that aesthetic point of view. The result of this study found that the language style and the interpretation of the Quran and hadith have influenced the uslub (style) and the contents of the poetry of al-Imam al-Shafi'i. In addition, the aspects of balaghah, such as tibaq, jinas, qasr, taqdim, ta'khir, tashbih, in addition to proper selection of words has reinforced the aesthetics in the poems and highlighted the creativity of this great scholar.
\end{abstract}

Keywords: aesthetics, poetry, rethoric, al-Shafi'i, stylistic

Setiap unsur yang membina karya sama ada yang eksplisit mahu pun implisit saling mempunyai kaitan antara sama lain. Antara sudut yang boleh dikaji untuk mengangkat kedudukan sesuatu karya ialah nilai estetik bahasanya. Walaupun sarjana silam memiliki kepakaran dalam segenap cabang ilmu, namun mereka tetap mengambil berat elemen bahasa dalam karya mereka. Antara ulama masyhur yang kekal menjadi rujukan ialah al-Imam al-Shafi'i (r.a.). Kewibawaan beliau dalam bidang usul fiqah dan fiqah tidak dapat disangkal lagi. Namun masyarakat kurang mengenali beliau sebagai tokoh sastera Arab. Oleh itu, kajian ini wajar dilakukan bagi mengetengahkan kebolehan beliau dari sudut ilmu bahasa Arab lantaran pengiktirafan ramai ilmuwan terhadapnya. Kajian ini menggunakan metode kualitatif dengan menjadikan analisis kandungan sebagai reka bentuk kajian. Pengumpulan data dilakukan terhadap bait-bait yang berkaitan dunia seterusnya dianalisis dari sudut estetiknya. Hasil kajian ini mendapati gaya bahasa serta tafsiran al-Quran dan hadis mempengaruhi uslub dan kandungan puisi Imam Shafi'i. Selain itu, aspek balaghah seperti tibaq, jinas, qasr, taqdim dan ta'khir, tashbih, ditambah pula dengan pemilihan kata yang sesuai turut mengukuhkan estetik dalam bait puisi beliau serta menyerlahkan kekreatifan sarjana agung ini.

\footnotetext{
${ }^{1}$ Moktar Hussain*(Corresponding author), B.A. language teacher at Arabic Language Unit, Faculty of Islamic Studies, Universiti Kebangsaan Malaysia, 43600 BANGI, Selangor, Malaysia, email: moktar@ukm.edu.my; Khazri Osman, Ph.D., senior lecturer at Department of Da'wah and Leadership, Faculty of Islamic Studies, Universiti Kebangsaan Malaysia, 43600 BANGI, Selangor, Malaysia, email: khazri@ukm.edu.my.
} 


\section{Permasalahan Kajian}

Ungkapan mahupun ujaran dalam bahasa Arab terbahagi kepada dua kategori; manzum dan manthur. Dari segi nilainya pula, yang manzum itu lebih baik daripada manthur kerana walaupun manthur itu banyak dan nampak indah kurang mempengaruhi sasaran. Manakala manzum pula sungguhpun bilangannya sedikit dalam karya tetapi terbaik (Ibn Rashiq 1981). Dalam hal ini, prosa diklasifikasikan sebagai manthur manakala puisi ialah manzum. Manusia sentiasa berusaha meluahkan perasaan dan buah fikirannya sama luahan itu positif atau negatif. Maka puisi dicipta sebagai salah satu wahana menggambarkan sesuatu yang terbuku di hati. Idea yang terdapat dalam kotak minda seseorang hanya dapat diterjemahkan dengan ungkapan yang sesuai bagi memudahkan golongan sasaran memahaminya. Dalam hal ini peranan bahasa amat penting. Hanya susunan bahasa yang indah dan memiliki nilai estetik sahaja dapat menyampaikan maksud sebenar. Maka, puisi al-Imam al-Shafi'i sesuai dianalisis untuk menonjolkan nilai estetiknya. Ulama mempunyai nasabah dengan Rasulullah (s.a.w.) ini lebih dikenali sebagai faqih, meskipun beliau kemahiran beliau dalam cabang ilmu bahasa Arab amat mantap. Kebolehan beliau menyusun karya telah diakui oleh Azhari (t.th.) yang mendapati alImam al-Shafi'i merupakan seorang yang sangat berpengetahuan, memiliki basirah yang tajam, pandai menerangkan maksud, mempunyai tutur kata yang fasih serta lafz yang mantap. Teori yang mengkaji keindahan bahasa menekankan keindahan karya sastera yang bermutu seharusnya mencakupi dua aspek; luaran atau fizikal dan dalaman atau isinya. Keindahan luaran termasuklah aspek bahasa, susunan idea, pilihan watak, latar dan waktu. Keindahan dalaman pula berkisar pada kesan dan tujuan karya tersebut dicipta, yang akhirnya membawa kepada kesan yang baik kepada golongan sasaran (Hazami Jahari 2014). Gambaran keindahan atau artistik sesuatu karya boleh dinilai melalui perkataan dan ayat yang disusun oleh pengkaryanya yang mengaplikasikan segenap cabang ilmu bahasa seperti dilalah, haqiqah, majaz, antonim, sinonim, muqabalah, jinas dan sebagainya. Jelas di sini, cabang ilmu balaghah sangat berkait rapat dengan ilmu estetika. Tambahan pula, analisis bahasa dari sudut linguistik lebih mudah dilakukan terhadap gaya atau tulisan yang tidak terlalu panjang, seperti puisi. Hal yang demikian sebaliknya terjadi apabila menganalisis novel, kerana kaedah linguistik lebih tersedia untuk menjelaskan karya yang agak ringkas berbanding novel yang biasanya panjang (Mohammad Fadzeli 2017).

\section{Puisi Imam Shafi'i}

al-Imam al-Shafi'i mempunyai pandangan tersendiri terhadap puisi. Ini terserlah melalui katakatanya: "Puisi itu merupakan salah satu jenis kata-kata yang tersusun. Ada yang baik dan ada yang buruk" (al-Zuhayli 1996). Namun beliau enggan meneruskan minatnya terhadap puisi lalu memilih untuk menekuni bidang fiqah. Kebanyakan puisinya menjurus kepada hikmah, nasihat dan bimbingan serta dipersembahkan dalam bentuk yang senang difahami, ringkas, perkataan yang mudah dan ayat yang jelas. Tiada qasidah yang terlalu panjang kerana puisinya disampaikan secara spontan. Demi mempertahankan seni warisan bahasa Arab khususnya puisi, para ilmuwan telah berusaha gigih mengumpul bait-bait puisi al-Imam al-Shafi'i untuk dikaji dan dianalisis.

\section{Latar Belakang Imam Shafi'i}

Beliau ialah Muhammad bin Idris bin al-'Abbas bin Uthman, bin Shafi', bin al-Saib, bin cUbayd, bin 'Abd Yazid, bin Hashim, bin `Abd al-Muttalib bin `Abd Manaf (al-Asbahani 1974). `Abd Manaf ialah datuk Rasulullah (s.a.w.) yang ketiga. Laqab al-Shafi'i dikaitkan dengan datuk beliau yang ketiga iaitu Shafi'. Al-Imam al-Shafi'i dilahirkan pada tahun 150 Hijrah di Gaza, Palestin. Sewaktu berusia dua tahun, ibunya membawa beliau ke Makkah. Demi mendalami ilmu bahasa 
Arab, al-Imam al-Shafi'i menetap selama tujuh belas tahun bersama kabilah Hudhayl. Kabilah ini cukup terkenal kerana mempunyai tahap kefasihan bahasa Arab yang tinggi. Beliau mempelajari bahasa, pertuturan dan cara hidup mereka. Apabila kembali ke Makkah, beliau terus berpuisi, sastera dan kisah orang Arab zaman silam. Seterusnya al-Imam al-Shafi'i pergi ke Madinah Munawwarah mengutip mutiara ilmu daripada Imam Malik bin Anas, mendalami kitab al-Muwatta' dan berjaya menghafalnya dalam tempoh sembilan hari. Ketika membaca alMuwatta' di hadapan Imam Malik, beliau selaku pengarang al-Muwatta' berasa kagum dengan kefasihan dan kelancaran al-Imam al-Shafi'i meskipun usianya pada ketika itu baru mencecah tiga belas tahun (Ibn `Asakir 1995). Selepas kematian Imam Malik pada tahun 179 Hijrah, alImam al-Shafi'i mengembara ke Kufah dan Basrah untuk menuntut ilmu daripada para ulama. Kemudian beliau mengajar di Masjidil Haram selama sembilan tahun. Di Baghdad, beliau menjadi rujukan ramai terutamanya golongan ulama, ahli hadis dan ahli al-ra'y. Di situ juga beliau mengambil peluang mengarang al-Risalah yang membicarakan tentang usul fiqah. Beliau terus berkarya sehingga menghasilkan kira-kira 113 buah penulisan. Mulai tahun 199 Hijrah, beliau menetap di Mesir sehingga meninggal dunia pada tahun 204 Hijrah dan dikebumikan di Kaherah (al-'Aqbawi 2007).

\section{Perbincangan}

Nukilan daripada bait puisi oleh al-Imam al-Shafi'i (Bahjat 1999):
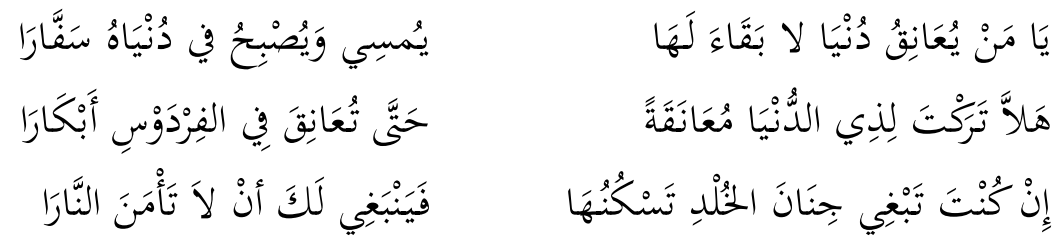

Maksudnya: Wahai orang yang mendakap dunia yang tidak kekal, sentiasa mengembara pada waktu pagi dan petang. Tinggalkan kecintaan terhadap dunia, agar engkau boleh memeluk bidadari di syurga. Jika engkau mahu tinggal di syurga yang kekal abadi, maka sewajarnya engkau tidak berasa terselamat daripada api neraka.

Kata kerja 'anaqa-yu 'aniqu oleh seorang bapa terhadap anaknya bermaksud perbuatan menghampirkan leher kepada si anak serta mendakap pada dada sebagai tanda kasih (Ahmad Mukhtar 2008). Kalimah ini dipilih oleh al-Imam al-Shafi'i dalam bentuk figuratif serta bersifat kiasan bagi mencerminkan betapa kuatnya cinta seseorang terhadap dunia. Hubb didefinisikan oleh Abu Hilal al-'Askari (1988) sebagai kecenderungan hati dan fikiran tentang seseorang. Hal ini berbeza daripada wudd yang hanya melibatkan kecenderungan hati sahaja. Jelas di sini, orang yang cintakan dunia bermakna fikiran dan hatinya telah ditakluki oleh keduniaan. Manakala dunia berasal daripada perkataan Arab dunya bermaksud hampir, sesuai dengan kedudukannya yang dekat dengan manusia manakala akhirat itu terkemudian (al-Azhari 2001). Al-Imam al-Shafi'i mengemukakan dunya dalam keadaan nakirah untuk merendahkan martabat dunia ini. Sama keadaannya dengan penampilan nakirah kalimah mata' dalam ayat Ghafir 40: 39:

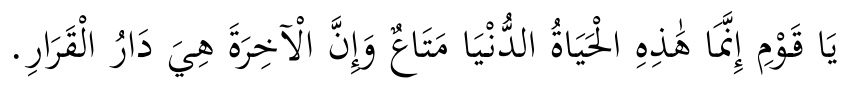


Maksudnya: Wahai kaumku! Sesungguhnya kehidupan dunia ini hanyalah kesenangan (untuk sementara waktu sahaja), dan sesungguhnya hari akhirat itulah sahaja negeri yang kekal.

Menurut al-Maydani (1996), mata ' hadir dalam bentuk nakirah mencerminkan sifatnya yang kecil, hina dan mudah hilang. Penampilan kedua-dua perkataan yumsi - yusbih dalam bentuk antitesis atau tibaq. Taqabul makani di sini berperanan untuk mendapatkan kesan perbezaan atau pertentangan yang seimbang. Saffar ialah sighah mubalaghah bagi menekankan betapa benarnya keadaan manusia yang mengembara pagi dan petang sewaktu berada di dunia. Kandungan bait puisi ini dilihat mempunyai maksud yang hampir seiras dengan sabda Rasulullah (s.a.w.) sewaktu menepuk bahu Abdullah bin `Umar r.a. (al-Bukhari 2001, juz. 8: 89).

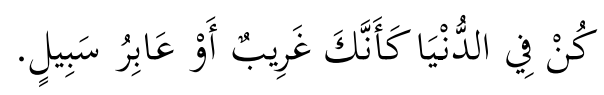

Maksudnya: Jadilah kamu di dunia ini seakan-akan orang asing atau seorang pengembara.

Ibn `Umar berkata selanjutnya dalam Hadis yang sama:

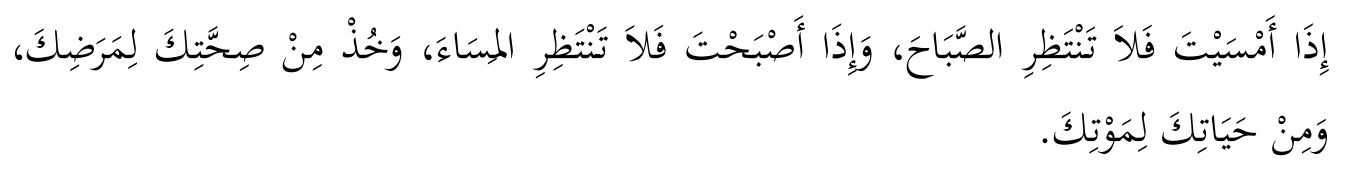

Maksudnya: Bila kamu berada pada waktu petang, janganlah kamu menunggu datangnya waktu pagi. Apabila kamu berada pada waktu pagi, janganlah menunggu waktu petang. Gunakanlah waktu sihatmu sebelum tiba waktu sakitmu, dan waktu hidupmu sebelum matimu.

Dalam ungkapan Ibn “Umar ini "amsayta" didahulukan berbanding asbahta sedangkan kebiasaannya disebut 'pagi, petang'. Namun apa yang menariknya ungkapan Ibn 'Umar turut mempengaruhi puisi al-Imam al-Shafi'i yang mendahulukan yumsi berbanding yusbih.

Firdaws dalam bahasa Syam bermaksud kebun. Menurut Mujahid, firdaws berasal daripada bahasa Rom yang kemudiannya diistilahkan ke dalam bahasa Arab (Ibn `Ashur 1984). Dalam puisi ini, al-Imam al-Shafi'i memaksudkan syurga tertinggi sebagai satu motivasi ke arah amal kebaikan. Pendekatan ini juga pernah diucapkan oleh Rasulullah (s.a.w.) terhadap Umm Harithah yang sedang bersedih lantaran anaknya Harithah terkena panah semasa pertempuran Badr (al-Tirmidhi 1975, juz. 4: 175).

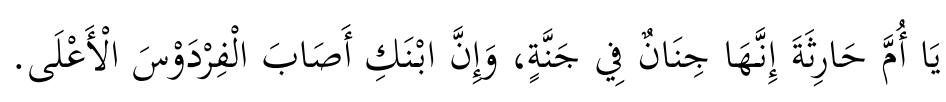

Maksudnya: Wahai ibu Harithah, sesungguhnya syurga itu ada berbagai-bagai. Anakmu mendapat yang tertinggi iaitu Firdaus.

Pendahuluan fi al-fardaws berbanding maf ul bih iaitu abkara bertujuan takhsis kerana hanya dalam syurga sahaja terdapat bidadari. Takhsis ini bersesuaian dengan pandangan Ibn Kathir (1998) bahawa penghuni syurga akan sibuk memecahkan keperawanan bidadari yang masih suci. Selanjutnya, al-`Aqbawi (2007) dan Muhammad `Abd al-Rahim (1995) menukilkan bait puisi oleh Imam Shafi'i: 

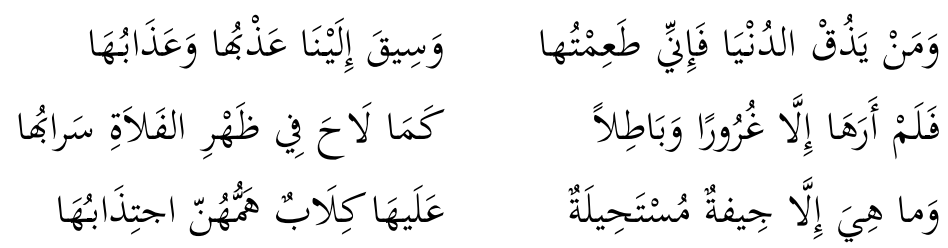

Maksudnya: Sesiapa yang merasai dunia, sesungguhnya aku telah merasainya, kita diberi perkara yang positif dan negatif daripada dunia.

Aku melihat dunia ini sekadar penipuan dan kebatilan, sebagaimana munculnya fatamorgana di kawasan yang luas.

Dunia ini seperti bangkai yang berubah, mengandungi anjing yang mahu mendapatkannya.

Asal makna dhawq ialah merasai makanan dengan lidah. Dalam al-Quran, dhawq digunakan sebagai majaz apabila dikaitkan dengan azab yang bakal dirasai oleh pesalah. Pesalah bukan sekadar merasai azab bahkan dia seolah-olah menelannya seperti makanan. Sentuhan dengan lidah lebih sensitif berbanding menggunakan tangan atau kulit (Ibn `Ashur 1984). Kehadiran kata kerja ta `imtuhu menguatkan lagi makna dhawq ini, bagi mengingatkan tentang sikap pencinta akan dunia yang menyuap, menggigit, mengunyah, dan memasukkan dunia ke dalam perut melalui kerongkongan. Antara dua kata, 'adhbuha dan 'adhabuha ada jinas ghayr tam yang menambahkan keindahan bait ini. Dalam bait kedua, pemuisi menyifatkan dunia ini seperti ghurur, sama seperti penggunaannya dalam al-Quran surah Ali 'Imran (3:185) al-Hadid (57:20). Menurut al-Maydani (1996) dan Hashimi (1999), jika sifat yang dikaitkan dengan maqsur 'anh tidak boleh dimiliki oleh makhluk lain, maka qasr itu dikategorikan sebagai haqiqi. Misalnya "tiada tuhan selain Allah (s.w.t.)" atau "tiada pemberi rezeki selain Allah (s.w.t.)." Namun, jika maqsur 'anh turut memiliki sifat lain selain yang dinyatakan, maka qasr itu dikategorikan sebagai idafi. Contohnya dalam firman Allah dalam surah Ali 'Imran 2: 144:

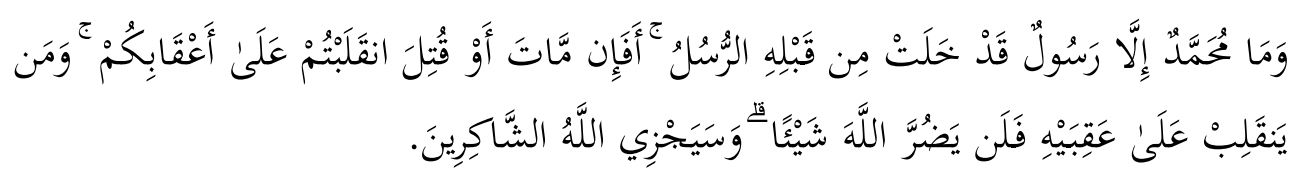

Dalam ayat ini, Nabi Muhammad bukan sekadar bersifat utusan Allah (s.w.t.), bahkan turut memiliki sifat-sifat lain sebagai manusia. Berdasarkan hujah ini, maka qasr yang terkandung dalam bait kedua dan ketiga dikategorikan sebagai qasr idafi, qasr mawsuf (dunia) 'ala sifat. Tujuan qasr di sini untuk meyakinkan golongan sasaran bahawa dunia memang bersifat penipu, batil dan umpama bangkai. Falat bermaksud kawasan yang jauh lokasi airnya (Sahib al-Talqani 1994). Pemuisi mengumpamakan penipuan dunia ini seperti orang kehausan yang terpedaya melihat kawasan berair di padang pasir, sama seperti pendapat Abu Hilal al'Askari (1988), yang mendefinisikan ghurur sebagai pendayaan yang menyebabkan manusia melakukan sesuatu yang boleh membinasakannya. Ibn Kathir (1998) turut menjelaskan, dunia mendayakan orang yang cenderung ke arahnya. Ketakjuban seseorang terhadap dunia menyebabkan dia menyangka tiada lagi rumah dan tempat kembali selain dunia ini. Dalam bait ketiga, perumpamaan dunia seperti bangkai yang dicari oleh anjing juga ada kebenarannya. Walaupun ungkapan "Dunia ini umpama bangkai dan pencarinya seperti anjing" bukan berasal daripada Rasulullah (al-'Ajluni 2009), namun ungkapan ini ada kebenarannya kerana dunia ini tidak ada nilainya di sisi Allah (s.w.t.) walaupun seberat sebelah sayap nyamuk. Manusia pula dilarang menjadi pencinta akan dunia. 


\section{Tanda-Tanda Hubb al-Dunya}

Hubb didefinisikan oleh Abu Hilal al-'Askari (1988) sebagai kecenderungan hati dan fikiran tentang seseorang. Hal ini berbeza daripada wudd yang hanya melibatkan kecenderungan hati sahaja. Jelas di sini, orang yang cinta akan dunia bermakna fikiran dan hatinya telah ditakluki oleh keduniaan. Gabungan hubb dan dunya, bermaksud hati dan fikiran seseorang yang minat terhadapnya. Dari segi istilah cinta akan dunia terjadi apabila seseorang itu menganggap dunia ini sebagai tuhan yang menguasai dan dirinya umpama hamba. Dia juga beranggapan bahawa dia akan kekal selama-lamanya atas dunia, tanpa memikirkan soal kematian dan apa selepasnya (Qaradawi 2013). Dunia merupakan tempat sementara untuk menuju akhirat. 'Isa (a.s.) menganalogikan orang yang cinta akan dunia ini seperti membina rumah di atas ombak kerana binaan itu tidak akan kekal (al-San`ani 2011). Rasulullah pula menganggap dirinya tidak ubah seperti pengembara yang singgah sebentar berteduh di bawah pokok dan akan meneruskan perjalanan. Setelah melalui kehidupan dunia, manusia menghadapi alam kubur dan seterusnya dibangkitkan kembali untuk alam akhirat. Kehidupan dunia adalah keseronokan yang tidak kekal, permainan, makan, dan minum (al-Qurtubi 1964). Oleh hal yang demikian, menurut 'Azim Abadi (1995) cinta akan dunia biasanya dikaitkan dengan benci terhadap kematian. Mengingati mati sangat penting menurut pandangan Ibn Diqaq kerana dengan mengingati mati mampu menjadikan seseorang segera bertaubat, memiliki hati yang qana'ah dan rajin beribadah (al-Qurtubi 1995). Sufyan al-Thawri mengingatkan, akan tiba masanya perasaan cinta akan dunia memenuhi hati manusia sehingga menghilangkan rasa gerun kepada Allah (s.w.t.). Perumpamaannya seperti sebuah bekas yang dipenuhi air menyebabkan tiada ruang untuk dimasuki oleh benda lain (al-Asbahani 1974). Pada waktu yang sama hati terasa hambar untuk zikrullah sedangkan Sulayman al-Khawwas menegaskan hati memerlukan zikir seperti tubuh badan memerlukan makanan. Ujian kesakitan menghilangkan selera makan. Sama halnya dengan hati yang tidak mendapat kelazatan berzikir apabila dihalang oleh cinta terhadap dunia (Ibn Taymiyah 1987).

Dari segi keikhlasan beramal pula, hubb al-dunya boleh terjadi apabila seseorang melakukan amalan akhirat tetapi mengharapkan habuan dunia. Contohnya menuntut ilmu untuk menyaingi ulama, berdebat dengan orang jahil, atau mengharapkan orang ramai tertumpu kepadanya. Termasuk juga orang yang melakukan haji untuk orang lain tetapi sematamata mengharapkan upahnya, berjihad demi mengharapkan ghanimah, mempelajari al-Quran serta rajin menunaikan solat kerana mengharapkan agar memperoleh habuan tertentu. Apabila keikhlasan mulai tergugat maka terjadilah pengeluaran hukum tanpa didasari oleh ilmu. Menurut Ibn al-Qayyim (1973) orang alim dan penguasa yang cinta akan dunia menyanggah kebenaran demi nafsu dan kedudukan. Jika berlaku pertindihan antara kehendak nafsu dan perkara syubhah, nafsu akan bertindak balas sekalipun kebenaran itu jelas dan nyata.

Dari segi penampilan diri dan gaya hidup, hubb al-dunya akan berlaku apabila insan sanggup berhabis demi memenuhi kehendak nafsu. Sekalipun hal ini diharuskan syarak namun jika berlebihan ia dikhuatiri boleh melalaikan insan daripada mengingati Allah (s.w.t.) dan benci terhadap kematian (Munawi 1988). Sabda Rasulullah (s.a.w.) kepada Mu`adh bin Jabal sewaktu mengutusnya ke Yaman (Ahmad 2001, juz. 36: 420):

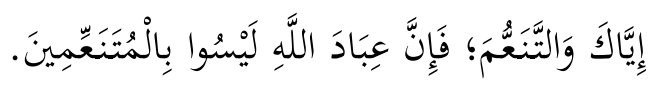

Maksudnya: Janganlah kamu terlampau memenuhi kehendak nafsu. Sesungguhnya hamba-hamba Allah yang benar-benar ikhlas tidak melampau dalam memenuhi kehendak nafsu. 
Keterlampauan dalam berpakaian boleh menyebabkan seseorang itu sukar melakukan kerja yang rumit dan boleh membawa kepada riyak. Berlebih-lebihan dalam makan pula menyebabkan malas dan lalai (al-Safarini 1993).

Sebagai kesimpulan, kewibawaan al-Imam al-Shafi'i bukan sekadar dalam fiqah, bahkan dalam bidang bahasa dan kesusasteraan juga. Bait-bait terpilih yang dianalisis menunjukkan puisi beliau memiliki nilai estetik yang terbaik yang diresapi oleh pengaruh al-Quran dan hadis. Selain itu, unsur balaghah termasuk pemilihan perkataan dan ungkapan yang menarik sebagaimana diketengahkan oleh sarjana lampau turut mengukuhkan puisi beliau. Peranan manusia diperlukan untuk mentadbir dunia. Namun, beliau mengingatkan manusia agar tidak terpedaya dengan keindahan dunia yang sementara. Peringatan yang disampaikan dalam bentuk sindiran sinis dan tajam menjadikan nasihat beliau kekal relevan sepanjang zaman. Kajian lanjut diperlukan bagi menjadikan puisi beliau setanding dengan karya-karya tasawuf yang dihasilkan oleh Imam al-Ghazzali, Ibn `Ata'illah al-Sakandari dan lain-lain.

\section{References}

Al-Qur'an.

Abu Hilal al-`Askari, Al-Hasan `Abdullah. 1988. Al-Furuq al-Lughawiyyah. Egypt: Dar al-`Ilm wa al-Thaqafah.

Ahmad. 2001. Musnad Ahmad. Musnad al-Ansar. Juz 36.

al-Asbahani, Ahmad 'Abdullah. 1974. Hilyah al-Awliya'. Cairo: Al-Sa`adah.

al-Azhari, Muhammad Ahmad. 2001. Tahdhib al-Lughah. Beirut: Dar Ihya' al-Turath al-`Arabiyy. al-Azhari, Muhammad Ahmad. t.th. Al-Zahir fi Gharib Alfaz al-Shafi ì. Cairo: Dar al-Talai'.

al-'Ajluni, Isma il bin Muhammad. 2009. Kashfal-Khafa'. Beirut: Dar al-Kutub al-'Ilmiyyah.

al-`Aqbawi, Isma`il. 2007. Diwan al-Imam al-Shafi ì. Cairo: Dar al-Haram li al-Turath.

'Azim Abadi, Muhammad Ashraf. 1995. 'Awn al-Ma`bud ma`a Hashiyah Ibn Al-Qayyim. Beirut: Dar al-Kutub al-'Ilmiyyah.

Bahjat, Munjid Mustafa. 1999. Diwan al-Shafi i. Damascus: Dar al-Qalam.

al-Bukhari. 2001. Kitab al-Riqaq, bab Qawl al-Nabiyy Salla Allahu `Alayhi wa Sallam Kun Fi alDunya Ka Annaka Gharib aw `Abir al-Sabil. Sahih Bukhari. juz 8.

Hashimi, Ahmad Ibrahim. 1999. Jawahir al-Balaghah. Beirut: Dar al-Fikr.

Ibn al-Qayyim, Muhammad Abu Bakr. 1973. Fawaid. Beirut: Dar al-Kutub al-'Ilmiyyah.

Ibn `Asakir, `Ali al-Hasan. 1995. Tarikh Dimashq. Beirut: Dar al-Fikr.

Ibn `Ashur, Muhammad al-Tahir Muhammad. 1984. Al-Tahrir wa al-Tanwir. Tunis: Dar alTunisiyyah.

Ibn Kathir, Isma il 'Umar. 1998. Tafsir Al-Quran al- 'Azim. Beirut: Dar al-Kutub al-'Ilmiyyah.

Ibn Rashiq, al-Hasan ibn Rashiq. 1981. Al-'Umdah. Beirut: Dar al-Jil.

Ibn Taymiyah, Ahmad `Abd al-Halim. 1987. Al-Fatawa al-Kubra. Ahmad al-Barduni (pnyt.). Beirut: Dar al-Kutub al-'Ilmiyyah.

al-Maydani, `Abd al-Rahman Habannakah. 1996. Al-Balaghah al-'Arabiyyah. Damascus: Dar alQalam.

Mohammad Fadzeli Jaafar. 2017. Stalistik Dalam Cereka. Kuala Lumpur: Dewan Bahasa Dan Pustaka.

Muhammad `Abd al-Rahim. 1995. Diwan al-Imam al-Shafi i. Beirut: Dar al-Fikr.

al-Munawi, `Abd al-Rauf Taj al-`Arifin. 1988. Al-Taysir bi Sharh al-Jami` al-Saghir. Riyadh: Maktabah al-Imam al-Shafi i.

al-Qaradawi, Yusuf 'Abdullah. 2013. Min Amrad al-Ummah: Hubb al-Dunya. http://www.qaradawi.net/news/6053.html [June 25, 2014].

al-Qațt, Abd al-Qadir. 1988. Al-Ittijah al-Wujdani fi al-Shi'r al- ${ }^{c}$ Arabiyy al-Mu'āsir. Cairo: Maktabah al-Shabab.

al-Qurtubi, Muhammad Ahmad. 1964. Tafsir al-Qurtubi. Ahmad al-Barduni (pnyt.). Cairo: Dar 
al-Kutub al-Misriyyah.

al-Qurtubi, Muhammad Ahmad. 1995. Al-Tadhkirah. Riyadh: Maktabah Dar al-Minhaj. al-Safarini, Muhammad Ahmad. 1993. Ghidha' al-Albab. Egypt: Muassasah Qurtubah. Sahib al-Talqani, Isma`il bin `Abbad. 1994. Al-Muhit fi al-Lughah. Beirut: `Alam al-Kutub. San`ani, Muhammad Isma il. 2011. Al-Tanwir Sharh al-Jami al-Saghir. Riyadh: Dar al-Salam. Tirmidhi. 1975. Abwab Fadail al-Jihad, bab Ma Ja'a fi Fadl al-Haras fi Sabil Allah. Sunan alTirmidh. juz 4.

al-Zuhayli, Wahbah Mustafa. 1996. Al-Tafsir al-Munir. Damascus: Dar al-Fikr. 